\title{
In-patient psychiatric rehabilitation services: survey of service users in three metropolitan boroughs
}

\author{
Colin Cowan, ${ }^{1}$ Alan Meaden, ${ }^{2}$ Martin Commander, ${ }^{2}$ Tom Edwards $^{3}$
}

The Psychiatrist (2012), 36, 85-89, doi: 10.1192/pb.bp.110.033365

${ }^{1}$ Sandwell Mental Health and Social Care NHS Foundation Trust;

${ }^{2}$ Birmingham and Solihull Mental Health NHS Foundation Trust; ${ }^{3}$ Dudley and Walsall Mental Health Partnership NHS Trust

Correspondence to Colin Cowan (colin.cowan@ntw.nhs.uk)

First received 6 Jan 2011, final revision 6 Nov 2011, accepted 21 Nov 2011

\begin{abstract}
Aims and method To examine care pathways and characteristics of service users across a range of in-patient rehabilitation settings: community, long-term complex care and high-dependency rehabilitation.

Results Significant differences were found for service users in the different units with respect to duration of stay, length of history, number of admissions, community team, physical health, social functioning, history of aggression and perceived risk if discharged.

Clinical implications Community service provision may not adequately meet the needs of the most disabled and access to appropriate move-on facilities for rehabilitation in-patients is insufficient. Remedying this requires collaboration between policy makers, commissioners and clinicians to ensure access to a comprehensive range of services.
\end{abstract}

Declaration of interest None.
Whereas recent attention has been focused on developments in community-based psychiatry, in-patient mental health rehabilitation services appear to exist virtually unnoticed at present. This may be in part due to the contextual history of a major contraction of these services within the UK National Health Service (NHS) and an emphasis away from rehabilitation psychiatry over the last quarter of a century. ${ }^{1}$ More recently, however, guidance has been developed by the Royal College of Psychiatrists about what type and degree of specialisation of rehabilitation services would be expected for a patient population of a certain size. ${ }^{2}$ This guidance includes a definition of five categories of in-patient rehabilitation facilities: secure rehabilitation, longer-term complex care, high-dependency rehabilitation, community rehabilitation and highly specialist services. Community rehabilitation units are nonintensively staffed units focusing on activities of daily living, psychological interventions and engagement with services. High-dependency units work with individuals who are highly symptomatic, have severe comorbid conditions, significant risk histories and challenging behaviours. Longer-term complex care is for people who have high levels of disability, complex comorbidity, limited potential for change and significant risk to their own health and safety or to others.

Rehabilitation psychiatry has been described as 'practically an evidence-free zone in modern psychiatry' ${ }^{3}$ and there are few published descriptions of in-patient rehabilitation services. ${ }^{4,5}$ A detailed survey of a local rehabilitation service was conducted across the two inner London boroughs of Camden and Islington in $2005 .{ }^{6}$ However, studies reviewing the provision of in-patient rehabilitation services across neighbouring NHS trust areas have seldom been undertaken.

This study aimed to develop a better understanding of in-patient rehabilitation settings by examining a range of such settings within a defined geographical area. This consisted of the three boroughs of Birmingham, Solihull and Sandwell within the West Midlands, covering a total population of approximately 1.5 million. ${ }^{7}$ The services were provided by two NHS mental health trusts.

\section{Method}

The study population consisted of the service users of all in-patient rehabilitation services at the time of the survey. These were defined as NHS managed and staffed non-acute units, with a stated aim of rehabilitation and providing 24hour care from mental health nurses and a dedicated consultant psychiatrist, and later categorised as community rehabilitation units, longer-term complex care and highdependency rehabilitation, using the definitions in Wolfson et $a{ }^{2}{ }^{2}$ Forensic units and designated low secure units were not included.

Data were obtained using a modified version of the Resident Profile, developed by the Royal College of Psychiatrists' Research Unit for the Mental Health Residential Care Study. ${ }^{8}$ The questionnaire was supported by guidance notes to achieve better standardisation and covered demographic and residential data, psychiatric history, diagnosis, current mental health and behavioural problems, danger to self and others, physical health, personal functioning, interpersonal relationships, future placement, legal status and global rating. 
The Birmingham and Solihull questionnaires were completed by the named nurse for each service user and supplemented with details from the case notes. The Sandwell questionnaires were completed by one of the investigators (C.C.) in collaboration with the senior nursing staff for the service. The data from the Birmingham and Solihull services was collected (by A.M.) between March and June 2007 and the Sandwell data in February and March 2008. The project proposal was determined by the National Research Ethics Service to be a service evaluation for which ethical committee approval was not required, and approval was obtained from the relevant clinical governance bodies in Sandwell Mental Health NHS \& Social Care Trust and in Birmingham \& Solihull Mental Health Trust.

Data were analysed using Statistical Package for Social Sciences 12.0.1 for Windows. Chi-squared tests were used to compare patient characteristics across the three types of unit covered by this survey.

\section{Results}

Ten services were identified with 109 service users, consisting of five community rehabilitation units (four were hospital units and one an NHS staffed and managed rehabilitation nursing home that functioned as a hospital unit, all of which fell into the community rehabilitation unit category in the Royal College of Psychiatrists' template for rehabilitation services ${ }^{2}$ ) with 44 service users $(40 \%)$, three longer-term complex care services with 36 service users (33\%) and two high-dependency rehabilitation units with 29 service users (27\%). Ninety-eight completed questionnaires were obtained, representing $90 \%$ of all current service users. There were some questionnaires returned without a complete set of responses and this is shown accordingly in the tables. None of the service users were currently in employment and only five were married. Sixtyfive were male $(66 \%)$ and thirty-three female (34\%). The overall mean age was 45 years: 40 in the community units, 52 in long term and 45 in high dependency, with no significant difference found across the units. In terms of ethnicity, 66 service users were White (67\%), 22 Black/ Black mixed (22\%) and 10 in other groups (10\%). Sixty-six service users had a diagnosis of schizophrenia (67\%), 26 had affective (depressive and bipolar) psychoses (27\%), 2 had personality disorder, 1 organic psychosis, 1 substance misuse and 1 was placed in the questionnaire's 'other' category.

A total of $75(77 \%)$ service users had come from another psychiatric ward before entering the in-patient rehabilitation units, with 44 of these from acute in-patient wards. Out of the other 23 service users, 2 in the highdependency services had come from prison, 3 in the longerstay complex services had come from residential care and 1 from their family home. In the community services, 8 had come from their own home and 9 from supported accommodation or residential care. The median length of stay at the time of the survey was 38 months (range 0-143): 14 months (0-80) in community services, 75 months (8-130) in longer-term care and 38 months (6-143) in highdependency services This difference between the three service types was significant (Kruskal-Wallis $\chi^{2}=41.00$, $P<0.0001)$. Further descriptive data are shown in Table 1 , with comparison between the three types of unit.

Table 2 shows the results for current social functioning and risk behaviours. Moderate/severe problems in social functioning were found in $88 \%$ and significant differences

\begin{tabular}{|c|c|c|c|c|c|c|}
\hline & $\begin{array}{l}\text { All, } n(\%) \\
(n=98)\end{array}$ & $\begin{array}{l}\text { Community, } n(\%) \\
\quad(n=41)\end{array}$ & $\begin{array}{l}\text { Long term, } n(\%) \\
\quad(n=30)\end{array}$ & $\begin{array}{l}\text { High dependency } \\
n(\%)(n=27)\end{array}$ & $\chi^{2}$ & $P$ \\
\hline \multicolumn{7}{|l|}{ Service history } \\
\hline On another hospital ward prior to entry & $75(77)$ & $24(59)$ & $26(87)$ & $25(93)$ & 12.99 & 0.002 \\
\hline First contact $<1$ year ago & $3(3)$ & $3(7)$ & $0(0)$ & $0(0)$ & - & NS \\
\hline First contact $>10$ years ago & $71 / 95(75)$ & $24(59)$ & $24 / 28(86)$ & $23 / 26(89)$ & 10.08 & 0.0006 \\
\hline No admissions & $3(3)$ & $0(0)$ & $2(7)$ & $1(4)$ & - & NS \\
\hline 5 or more admissions & $64 / 96(67)$ & $26 / 40(65)$ & $21(70)$ & $18(67)$ & - & NS \\
\hline$>5$ years in hospital in lifetime & $68(69)$ & $18(44)$ & $25(83)$ & $25(93)$ & 22.13 & $<0.0001$ \\
\hline$<3 / 12$ in hospital in lifetime & $5(5)$ & $4(10)$ & $1(3)$ & $0(0)$ & - & NS \\
\hline \multicolumn{7}{|l|}{ Current community team } \\
\hline Assertive outreach & $24(25)$ & $9(22)$ & $8(27)$ & $7(26)$ & & \\
\hline $\mathrm{CMHT} /$ early intervention & $29(30)$ & $22(54)$ & $6(20)$ & $1(4)$ & & \\
\hline None & $45(46)$ & $10(24)$ & $16(53)$ & $19(70)$ & 23.27 & $<0.0001$ \\
\hline \multicolumn{7}{|l|}{ Diagnosis } \\
\hline Schizophrenia & $66 / 97(68)$ & $29(71)$ & $23(77)$ & $14 / 26(54)$ & & \\
\hline Affective psychosis & $26 / 97(27)$ & $8(19)$ & $6(20)$ & $12 / 29(41)$ & & \\
\hline Other & $5 / 97(5)$ & $4(10)$ & $1(3)$ & $0(0)$ & 9.3 & 0.05 \\
\hline \multicolumn{7}{|l|}{ Mental status } \\
\hline Moderate/severe problems in at least & & & & & & \\
\hline one symptom domain & $75(77)$ & $30(73)$ & $22(73)$ & $23(85)$ & - & NS \\
\hline Moderate/severe alcohol/drug problems & $14(14)$ & $8(20)$ & $2(7)$ & $4(15)$ & - & NS \\
\hline \multicolumn{7}{|l|}{ Physical health } \\
\hline No physical health problem & $39(40)$ & $14(34)$ & $7(23)$ & $18(67)$ & 12.08 & 0.002 \\
\hline Moderate/severe health problem & $35(36)$ & $12(29)$ & $17(57)$ & $6(22)$ & 18.62 & 0.01 \\
\hline Currently detained under Mental Health Act & $42 / 97(43)$ & $10(24)$ & $10(33)$ & $22 / 26(85)$ & 25.26 & $<0.0001$ \\
\hline
\end{tabular}

CMHT, community mental health team; NS, not significant. 


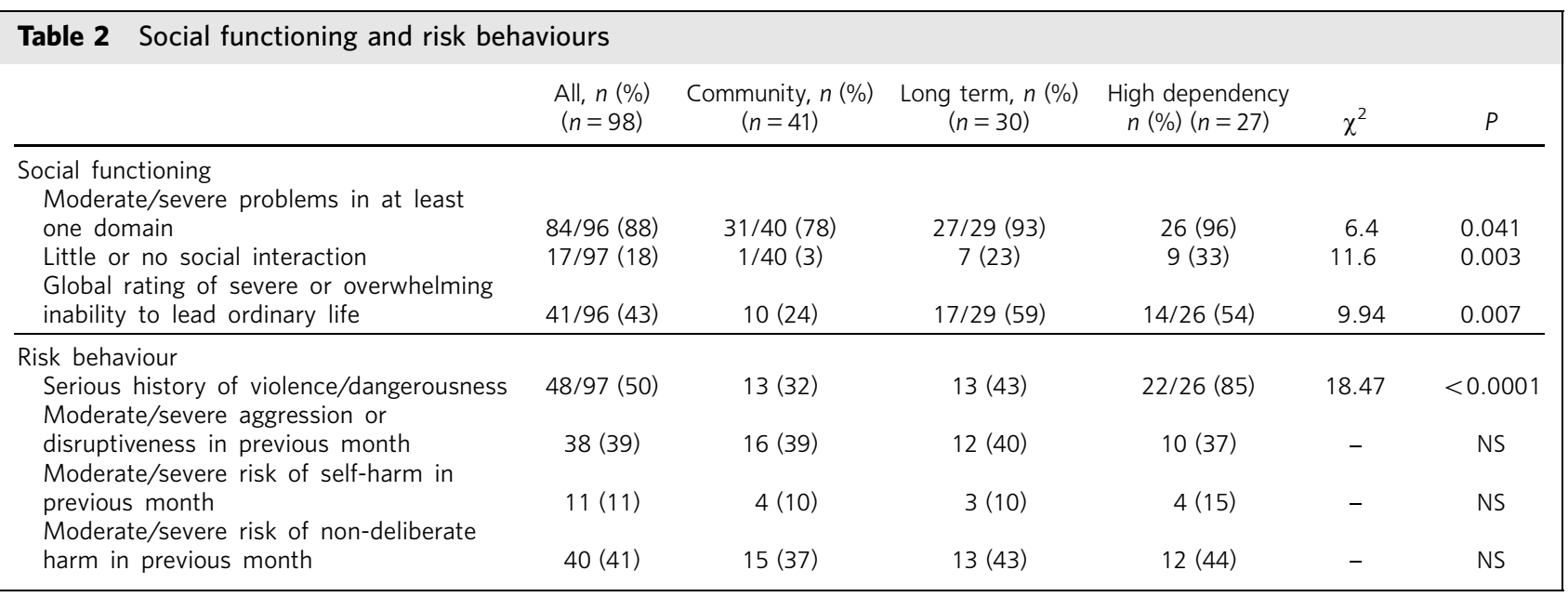

NS, not significant.

emerged between units in social functioning and history of violence, although not for risk behaviours displayed over the preceding month.

Table 3 shows the views of staff about suitability, placement issues and risks regarding discharge to less supervised settings. Nineteen $(19 \%)$ had been transferred unsuccessfully to another placement at some point and returned to the service, with no significant difference in this between the service types. Out of the 47 service users who were considered inappropriately placed in their current unit, for 20 this was because of no suitable move-on accommodation (12 because none was available and 8 because a suitable one had no vacancies) and for 9 because of lack of funding for an available place.

\section{Discussion}

This study has limitations in that there was a difference in data collection periods and procedure between services where collection of one data-set commenced 11 months after the rest and involved one of the investigators rather than being left with key informant nursing staff to complete. The investigation schedule was an adaptation of an older questionnaire and not a standardised instrument. Out-of-area in-patient and low secure placements were not considered and consequently it was not possible to analyse their care pathways in relation to the local rehabilitation services.

The service user group surveyed here was characterised by significant use of in-patient services over a long period, active psychiatric symptoms, poor social functioning and unsuitability for independent living, despite interventions over a prolonged period of time. Substantial numbers had recent aggression and problems anticipated by staff if discharged to less dependent settings. The survey also demonstrated the well-documented high rate of moderate or severe physical health problems in this group of service users. ${ }^{9}$ Overall, the range of in-patient rehabilitation units in this survey managed high levels of risk and disability. They also provided the opportunity for service users to move on to less supported settings but with limited availability of suitable facilities creating obstacles to this end.

Some significant differences emerged between the units. Those in community units had less extensive service histories. Those in high-dependency services were more likely to be considered appropriately placed, reflecting the

\begin{tabular}{|c|c|c|c|c|c|c|}
\hline & $\begin{array}{l}\text { All, } n(\%) \\
(n=98)\end{array}$ & $\begin{array}{l}\text { Community, } n(\%) \\
(n=41)\end{array}$ & $\begin{array}{l}\text { Long term, } n(\%) \\
\qquad(n=30)\end{array}$ & $\begin{array}{l}\text { High dependency } \\
n(\%)(n=27)\end{array}$ & $\chi^{2}$ & $P$ \\
\hline \multicolumn{7}{|l|}{$\begin{array}{l}\text { Moderate/severe risk if discharged } \\
\text { to independent setting }\end{array}$} \\
\hline Violence & $56 / 97(58)$ & $16(39)$ & $16(53)$ & $24 / 26(92)$ & 18.89 & $<0.0001$ \\
\hline Self-harm & $41 / 97(42)$ & $16(39)$ & $10(33)$ & $15 / 26(58)$ & - & NS \\
\hline Unintentional harm & $60 / 96(63)$ & $21(51)$ & $17 / 29(59)$ & $21 / 26(81)$ & 7.84 & 0.02 \\
\hline \multicolumn{7}{|l|}{$\begin{array}{l}\text { Anticipated problems if discharged to } \\
\text { less dependent setting }\end{array}$} \\
\hline attention & $89 / 95(94)$ & $36 / 40(90)$ & $28(93)$ & $25 / 25(100)$ & - & NS \\
\hline Severe/very severe problems & $43 / 95(45)$ & $9 / 40(23)$ & $18(60)$ & $16 / 25(64)$ & 14.54 & 0.001 \\
\hline \multicolumn{7}{|l|}{ Placement } \\
\hline Appropriately placed in current service & $50 / 97(52)$ & $19(46)$ & $12(40)$ & $19 / 26(73)$ & & \\
\hline Different in-patient setting appropriate & $18 / 97(19)$ & $4(10)$ & $8(27)$ & $6 / 26(23)$ & & \\
\hline Supported community setting appropriate & $24 / 97(25)$ & $15(37)$ & $8(27)$ & $1 / 26(4)$ & & \\
\hline Independent setting appropriate & $5 / 97(5)$ & $3(7)$ & $2(7)$ & $0(0)$ & 15.19 & 0.019 \\
\hline
\end{tabular}

NS, not significant. 
high risk of challenging behaviours that made less intensive settings untenable, and less likely to have an identified community team, which would have the effect of slowing referral out of the units. The individuals in high-dependency services were also more likely to have an affective psychosis, perhaps reflecting a group who are poorly engaged or whose condition is treatment resistant and who would not comply with open settings and could only be safely managed in a closed environment. The individuals in complex needs services were more likely to have severe physical health problems.

The overall findings were similar to another recent comparable survey ${ }^{6}$ in terms of gender balance, ethnicity, age and comorbid substance misuse but there were fewer diagnosed with schizophrenia or schizoaffective disorder and more admitted from a community setting, possibly reflecting the higher morbidity of the inner-city London context of that service. Comparing long-term in-patient with short-term in-patient groups showed older age, longer contact with services and poorer social functioning in both studies. In our study more of the long-term in-patient group were detained but lengths of stay were lower, perhaps reflecting fewer patients who had come from long-stay mental hospital wards.

The findings support the principle that different types of rehabilitation services are required. In particular, provision is clearly warranted for those with more marked, challenging or risk behaviours, many of whom continue to be detained under the Mental Health Act 1983. The large number of service users remaining in these services due to their risk potential if discharged highlighted the need for comprehensive risk assessment to facilitate therapeutic risk-taking as part of the process of rehabilitation.

The findings indicated two areas of unmet needs in users of rehabilitation services. The first was difficulties moving on when considered no longer appropriate for their current environment. The most common reason given for this was a lack of suitable move-on accommodation, a more frequent reason than unavailable funding. This highlighted the serious lack of a range of appropriate residential settings being readily available, particularly relevant for the longstay service user group. Similar results relating to the problems accessing appropriate move-on accommodation have been found among long-stay patients in acute admission wards. ${ }^{10}$ It appears that rehabilitation and acute services are attempting to access the same limited resources.

The greatest need was for supported residential settings reflecting less intensive needs, particularly for the community-unit service users. However, there was also a substantial requirement for ongoing intensive in-patient settings in the long-term service user group. Those in the high-dependency settings were the most likely to be considered appropriately placed, probably because this setting most clearly provided for the management of their enduring risk behaviours. Additionally, nearly half had no community team involvement, highlighting the risk of disconnection from community services, particularly for those in high-dependency services. This may result in longer than necessary stays since community care coordinators have a vital role in moving on, especially when moving from in-patient to supported or independent settings.
The second area of poorly met need was the availability of appropriate services for high levels of disability. This can be seen in the fact that a quarter were service users of assertive outreach teams, indicating that even the most highly resourced and intensive of community services for severe and enduring mental illness was still insufficient to maintain a substantial minority of such service users without residential services. Some service users were simply too disabled to be supported in the community. This may be related to the decline in rehabilitation services that took place in order to create assertive outreach teams in particular, with a corresponding focus away from reducing disability to management of risk ${ }^{1,11}$ and loss of close links with residential care services.

Commissioning strategies need to take account of a 'total system' approach in order to facilitate service users being able to move through the various types and stages of rehabilitation necessary to gain an increased degree of independence. $^{12}$ It has also been recommended that commissioners need to look towards developing specialised services nearer to home for service users, which could provide better care at a lower cost. ${ }^{13,14}$ Knowledge of the required types of rehabilitation in-patient services, and the corresponding size of population likely to need each type, ${ }^{2}$ is of critical importance to the collaborative working of commissioners and providers. Whereas only the very largest NHS trusts will be able to provide rehabilitation in-patient facilities up to the full complement of services advocated, ${ }^{2}$ smaller NHS trusts will need to orchestrate effective working between commissioners and providers in order to be able to access a similar range of services locally. Groups of neighbouring commissioners will increasingly need to work collaboratively in order to develop more local and specialised rehabilitation services.

\section{Acknowledgements}

We would like to thank the nursing staff of the ten rehabilitation services who provided invaluable assistance with data collection for this study.

\section{About the authors}

Colin Cowan is a consultant psychiatrist at Sandwell Mental Health \& Social Care NHS Foundation Trust. Alan Meaden is a consultant clinical psychologist at Birmingham and Solihull Mental Health NHS Foundation Trust. Martin Commander is a consultant psychiatrist at Birmingham and Solihull Mental Health NHS Foundation Trust. Tom Edwards is a consultant psychiatrist, Dorothy Pattinson Hospital, Walsall.

\section{References}

1 Holloway F. The Forgotten Need for Rehabilitation in Contemporary Mental Health Services. A Position Statement from the Executive Committee of the Faculty of Rehabilitation and Social Psychiatry, Royal College of Psychiatrists. Royal College of Psychiatrists, 2005 (http:// www.rcpsych.ac.uk/pdf/frankholloway_oct05.pdf).

2 Wolfson P, Holloway F, Killaspy H. Enabling Recovery for People with Complex Mental Health Needs. A Template for Rehabilitation Services. Royal College of Psychiatrists, 2009 (http://www.rcpsych.ac.uk/pdf/ fr_rs_1_forwebsite.pdf)

3 Killaspy $\mathrm{H}$, Harden $\mathrm{C}$, Holloway $\mathrm{F}$, King $\mathrm{M}$. What do mental health rehabilitation units do and what are they for? A national survey in England. J Ment Health 2005; 14: 157-65. 
4 Macpherson R, Butler J. Effect of treatment in an active rehabilitation hostel on the need for hospital treatment. Psychiatr Bull 1999; 23: 594-7.

5 Simpson S, Middleton N. Fast stream psychiatric rehabilitation after recent hospital closure. Psychiatr Bull 1994; 18: 613-4.

6 Killaspy H, Rambarran D, Bledin K. Mental health needs of clients of rehabilitation services: a survey in one trust. J Ment Health 2008; 17: 207-18.

7 Office of National Statistics. Population and Vital Statistics by Area of Usual Residence in the United Kingdom, 2006. ONS, 2008.

8 Lelliott $\mathrm{P}$, Audini B, Knapp M, Chisholm D. The mental health residential care study: classification of facilities and description of residents. $\mathrm{Br}$ Psychiatry 1996; 169: 139-47.

9 Connolly M, Kelly C. Lifestyle and physical health in schizophrenia. Adv Psychiatr Treat 2005; 11: 125-32.
10 Commander M, Rooprai D. Survey of long-stay patients on acute psychiatric wards. Psychiatr Bull 2008; 32: 380-3.

11 Mountain D, Killaspy $H$, Holloway F. Mental health rehabilitation services in the UK in 2007. Psychiatr Bull 2009; 33: 215-8.

12 Macpherson R, Shepherd G, Edwards T. Supported accommodation for people with severe mental illness: a review. Adv Psychiatr Treat 2004; 10: $180-8$.

13 Ryan T, Hatfield B, Sharma I, Simpson V, Mclntyre A. A census study of independent mental health sector usage across seven strategic health authorities. J Ment Health 2007; 16: 243-53.

14 Royal College of Psychiatrists, Mental Health Network, NHS Confederation and London School of Economics and Political Science. Mental Health and the Economic Downturn: National Priorities and NHS Solutions (Occasional Paper OP70). Royal College of Psychiatrists, 2009 (http://www.rcpsych.ac.uk/files/pdfversion/OP70.pdf).

\title{
Psychiatrists' experiences of stalking in Ireland: prevalence and characteristics
}

\author{
Izu Nwachukwu, ${ }^{1}$ Vincent Agyapong, ${ }^{2}$ Leah Quinlivan, ${ }^{1}$ John Tobin, ${ }^{3}$ Kevin Malone ${ }^{1}$
}

The Psychiatrist (2012), 36, 89-93, doi: 10.1192/pb.bp.111.034660

${ }^{1}$ University College Dublin; ${ }^{2}$ St Patrick's Hospital \& University of Dublin (Trinity College) Dublin; ${ }^{3}$ St Bricin's Hospital, Dublin, Ireland

Correspondence to Izu Nwachukwu (izunwachukwu@hotmail.com)

First received 20 Mar 2011, final revision 21 Nov 2011, accepted 28 Nov 2011
Aims and method Accumulating evidence suggest that psychiatrists may be at greater risk of being stalked compared with the general population. We used a selfadministered questionnaire to survey psychiatrists in Ireland about their experiences, practices and attitudes regarding work-related stalking.

Results We found that $25.1 \%$ of psychiatrists in Ireland had been the subject of stalking behaviour at some point in their career. At the time of the survey, $5.5 \%$ of respondents were actively being stalked. The majority of the stalking occurred in the workplace and most of the perpetrators were patients. Most of the victims were unaware of guidelines or other supportive mechanisms in their workplace. Of those who reported their experiences to authorities, almost half were not satisfied with the support they received.

Clinical implications Stalking of psychiatrists is not uncommon. Employers should put in place supportive structures backed up by education and training to reduce the incidence, associated morbidity and other wider consequences of stalking.

Declaration of interest None.
Since the 1990s, more attention has been paid to stalking and how it affects both victims and perpetrators. Enactment of the first anti-stalking legislation in California, USA, in 1990 and subsequent widespread criminalisation of stalking across other Western jurisdictions was quickly followed by increased media attention, research interest and clinical understanding of stalking and related behaviour patterns. Despite the accumulating body of knowledge, there remains considerable variation in what constitutes stalking from the clinical, research and legal perspectives. ${ }^{1}$

Stalking has been variously defined depending on the setting or context in which the behaviour is being assessed. Three key elements appear to be common to the majority of definitions found in literature. These elements include: (1) a pattern or course of behaviour that is directed at a person; (2) this behaviour is used to convey an implicit or explicit threat and/or is perceived by the target as unwanted and intrusive; and (3) an experience of fear or concern by the target. $^{2,3}$ As an example, Mullen and colleagues ${ }^{4}$ defined stalking as 'those repeated acts, experienced as unpleasantly intrusive, which create apprehension and can be understood by a reasonable fellow citizen (the ordinary man or woman) to be grounds for becoming fearful'.

In Ireland, stalking is covered by Section 10 of the NonFatal Offences against the Person Act that was enacted in 1997. As Irish society became aware of the legal protection against stalking, the incidents of recorded complaints to the police of stalking behaviour rose from 97 in 2000 to 759 in 2008. Notwithstanding this marked rise, the incidence of stalking in the general population is probably underreported.

Healthcare professionals are reported to have been stalked at rates higher than the general population. ${ }^{1}$ Mental 